\author{
Professor Constantin ANGHELACHE,PhD \\ E-mail: actincon@yahoo.com \\ The Bucharest University of Economic Studies \\ Associate Professor Mădălina-Gabriela ANGHEL,PhD \\ E-mail: madalinagabriela_anghel@yahoo.com \\ "ARTIFEX" University of Bucharest \\ Associate Professor Sorinel CĂPUSNEANU,PhD \\ E-mail: sorinelcapusneanu@gmail.com \\ "Dimitrie Cantemir" Christian University \\ Lecturer Dan Ioan TOPOR,PhD \\ E-mail:dan.topor@yahoo.com \\ University of Alba Iulia
}

\title{
ECONOMETRIC MODEL USED FOR GDP CORRELATION ANALYSIS AND ECONOMIC AGGREGATES
}

\begin{abstract}
This paper refers to the opportunities to utilize some econometric models in the macroeconomic studies. In this respect, authors concentrate on the possibility to use the simple linear regression model in analysing the evolution and correlation between the Gross Domestic Product and some macroeconomic aggregates. Under these circumstances, there are considered this macroeconomic indicator of outcomes as being the dependent variable, whose variation is significantly determined by the evolutions recorded by the parameters of the economic and social development of the country. The evolution of the Gross Domestic Product is supposed to be mainly influenced by the dynamics of the investments. However, in Romania, the current economic context is characterized by relatively low values of investments, at all stages, as the internal investments are very small as value, the foreign direct investments keep also low because, mainly, of the legal framework, and the absorption of European funds is not satisfactory. Therefore, at this stage, we focused on the investments and the final consumption as factors of GDP evolution. The value of the investments and the final consumption made at the level of Romania's economy has been defined as independent variables. It is extremely important to define the role played by the macroeconomic indicators as to increase/decrease the value of the Gross Domestic Product, generally speaking, and particularly in the case of Romania.
\end{abstract}

Key words: Gross Domestic Product, consumption, econometric model, simple linear regression, evolution.

JEL Classification: E01, E21, E22

DOI: 10.24818/18423264/53.1.19.12 


\section{Introduction}

The bigger and bigger increase of the complexity of the economic phenomena specific to the contemporary world generated a fundamental modification at the level of the typology of the analyses performed on this domain of activity. Presently, the discussion is focussing to an ever lower extent on the strict analyses of the evolution of a certain micro or macro indicator, the emphasize going more frequently to the analysis of the correlations existing between the evolution of two or more indicators specific to the economic system.

The simple linear regression model is representing a relatively easy and very efficient modality to set up the correlation between two economic indicators. When the results achieved by use of the linear regression are not sufficient for the explanation of a certain phenomenon, multiple linear regression should be used.

Thus, the utilization of this method of analysis in the macroeconomic researches allows the setting up of the way in which a certain macroeconomic variable, defined as being independent, determines the evolution of a second indicator of outcomes. In the frame of this paper, we pointed out the actual possibilities to utilize the linear regression model when analysing the evolution of the Gross Domestic Product influenced by different factors (variables). In order to underline the practical aspects concerning the utilization of the linear regression in the macroeconomic analyses, generally speaking, and in the analysis of the Gross Domestic Product in this particular case, we developed an empirical study in which frame the final consumption and investments at the level of the Romanian economy has been defined as independent variables. We have considered the final consumption and investments as relevant independent variables in the study of GDP evolution. The difficulties in attracting foreign investments and European funds are easy to observe, even if only by studying the values of these indicators. Also, the Romanian capital is not a strong presence in the economy, under the shape of autochthonous investments.

The choice of the indicator as reference point in the frame of the regression analysis was not a random one. Thus, in these researching steps we started from stating out the fact that the consumption and the investments are the main vectors of growth for the level of the Gross Domestic Product of any state. In this context, it is extremely important to define the role played by the indicator as to the increase/decrease of the value of the Gross Domestic Product of Romania.

\section{Literature review}

Stancuet. al. (2008) provide an introduction into econometrics based on the use of specialized software in econometric analyses. The works of Andrei and Bourbonnais (2008), and Benjamin et. al. (2010), are reference literature for any researcher using econometric model. Anghelache et. al. (2011, 2014), Corbae 
Econometric Model Used for GDP Correlation Analysis and Economic Aggregates

et.al.(2006), Ghysels and Osborn (2001) and Anghel (2014) approach the usefulness of econometric models in economic analyses. The data processed in this paper are collected from official sources (Romanian National Institute of Statistical, Romanian Statistical Year Book). vanEijck, and Majorana (2013) are preoccupied with researching the consumption patterns. Stanciu and Stoicuţa (2010) realize a valuation of the interconnection between the same indicators. Hindls and Hronova (2012) analyse the structure of final consumption in several countries, including Romania. Mazurek (2012) researches the GDP growth of European countries, for a period which is included in the timeframe of our study. Mandel and Tomšík (2003) develop a particular study on consumption. Heathcoteet. al. (2009) apply a quantitative approach on some macroeconomic issues. Nayyar (2007) and Vargas (2013) research the macroeconomic characteristics of developing countries. Soren and Nielsen (2010) develop on a fractionally co-integrated vector autoregressive model. Klär (2013) approaches the economic potential. Piroi and Păunică (2015) develop on the usefulness of modern IT instruments in the activity of the public administration. Goodwin (2008), Dougherty (2007) and Fox and Dodge (2012) offer valuable documentation for macroeconomic studies. Chamberlin (2011) researches the GDP as image of economic welfare.

\section{The methodology data, results and discussions}

- The econometric model of the analysis of the correlation between the Gross Domestic Product and the final consumption

The Gross Domestic Product perceived as one of the main macroeconomic aggregates specific to the National Accounts System, is representing the synthetic expression of the outcomes of the economic activity carried on within the economic territory during a given time interval, irrespectively of the contribution of the domestic or foreign subjects.

In the frame of the analysis performed on the factors which are generating the fluctuation of the Gross Domestic Product, we started from methodological elements typical for the method of the utilization of the final production (the expenses method), considering that this one is representing a source of significant information on the correlations influencing the evolution of the main macroeconomic aggregates. Thus, according to the above mentioned method of calculation, the Gross Domestic Product is established through the addition of those components expressing the utilization of the goods and services which are forming the final production, respectively: the final consumption $-\mathrm{CF}$, the capital gross forming - FBC and the net export - EXN.

Starting from the elements previously mentioned, we identified the relation existing at the level of Romania between the evolution of the final consumption 
(considered as a total of the two fundamental components - the private consumption and the public consumption) and the variation of the Gross Domestic Product. In this respect we used as method of analysis the simple linear regression. In the case of the simple linear regression we identified an econometric factorial model of the form:

where:

$$
y=\alpha+\beta^{*} x+\varepsilon
$$

$\mathrm{y}=$ the dependent variable;

$\alpha, \beta=$ the parameters of the regression model;

$\mathrm{x}=$ the independent variable;

$\varepsilon=$ the error term, representing the influences of the other factors of the variable $y$, non-specified in the model and considered as being random factors, with insignificant influences on the variable $y$.

In order to be in the position to build up a linear model of regression, we defined the final consumption as the independent variable, while the value of the Gross Domestic Product has been considered as being a dependent (resulting) variable.

From econometric point of view, the model taken into account must include also the error term, considered as a representation of the differences occurring between the values set up from a theoretical point of view and those measured in the frames of the real economy. Thus, the regression model can be transcribed as the following mathematical equation:

$$
\mathrm{GDP}=\alpha+\beta \cdot \mathrm{CF}+\varepsilon
$$

where:

GDP $=$ the Gross Domestic Product $\rightarrow$ dependent variable (explained, endogenous, resulting); exogenous);

GDP $=$ Final Consumption $\rightarrow$ independent variable (explanatory,

$\alpha, \beta, \rightarrow$ the parameters of the regression model;

$\varepsilon \rightarrow$ the error term.

In order to establish the parameters of this linear regression model, we considered a series of data concerning the evolution of the two macroeconomic parameters of outcomes over the period 1995 - 2015. The values of the two macroeconomic parameters have been deflated by using in this respect the index of the consumption prices (used by the National Institute for Statistics in order to calculate the inflation rate in Romania), which is showing the evolution of the final goods prices and services tariffs being acquired by the population during the current year as against the year 1990, chosen as reference period. The dataset covers the quarterly values, for a better representation of the correlation between the two indicators. The dataset was loaded in specialized software, under the series 
names GDP and CF. The access to information provided with the help of modern information technology instruments is useful for macroeconomic analyses.

To perform the analysis concerning the correlation existing between the two macroeconomic indicators, it is necessary to identify the particularities of the evolution of each and every value considered for the specified time interval. We have studied as a first stage, the individual evolution of the indicators. Thus, the study of the Gross Domestic Product of Romania during the period 1995 - 2015 allowed us to obtain the following information:

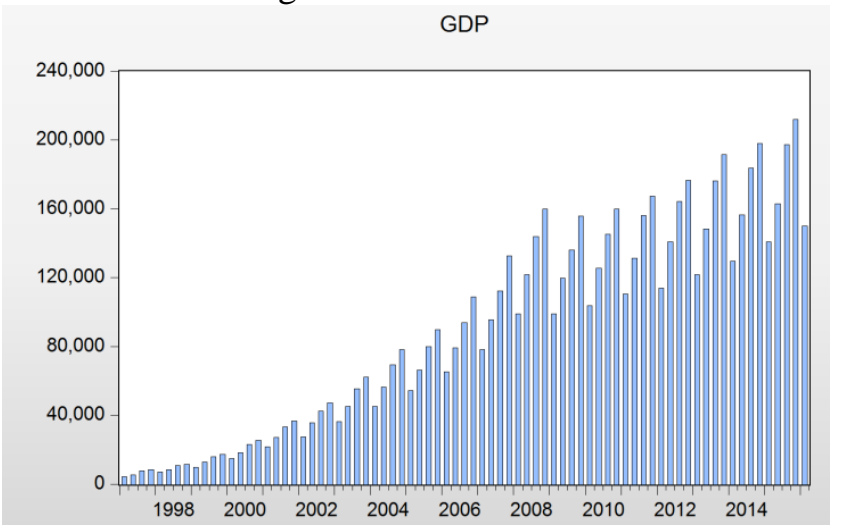

Figure 1.The evolution of the Gross Domestic Product of Romania during the period 1995 - 2015

As easily noticeable from figure 1 , during the considered time interval, the Gross Domestic Product of Romania recorded a constant increase from one year to another, with slight fluctuations of increases and decreases from the year 1995 up to the year 2008 when, on the ground of the economic and financial crisis which affected the whole world as from the second half of the year 2008, it is to state out the fact that the value of the Gross Domestic Product of Romania for the year 2009 recorded a decrease as comparatively to the previous time interval. As from the year 2011 until 2014, the Gross Domestic Product recorded an increase by $2.16 \%$ in the year 2012 as against 2011, by $2.75 \%$ in 2013 as against 2012 and by $3.49 \%$ in 2014 as against 2013 and $3.90 \%$ in 2015 against 2014.

With the support of a dedicated software package, we made a series of statistical tests meant to provide and secure an image as correct as possible on the evolution of the Gross Domestic Product of Romania during the period making the subject of the analysis. 


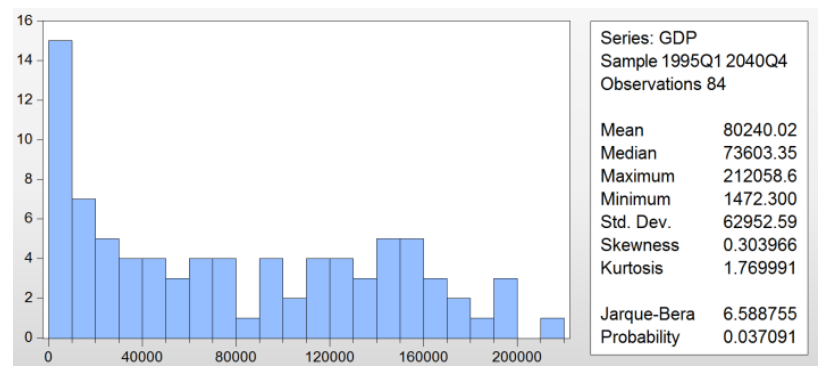

Figure 2.The main statistical tests applied on the value of the Gross Domestic Product of Romania during the period 1995 - 2015

Thus, we can notice the fact that average value of this indicator for the time interval 1995 - 2015 counts for 80,240 million RON, with a variation between a minimum of 1472.3 million RON (recorded by the end of Q1 1995) and a maximum of 212,058.5 million RON (measured by the end of the year 2015).

The values of the statistical tests made previously allow us to allege the fact that the distribution of the Gross Domestic Product values for the considered interval is not a perfectly symmetrical one (the value of the Skewness differs from zero), since the value of the Skewness test is higher than 0 we can affirm that the distribution is disposed to the left, having more extreme values to the right. The value of the Kurtosis test being smaller than 3, it means that we are having a platikurtic distribution, flatter than a normal distribution with values spread over a bigger interval around the mean. The probability for extreme values is smaller as comparatively with the case of a normal distribution.

A similar analysis can be made as to the evolution of the final consumption during the considered time interval. The main information obtained as a consequence of the analysis made with the assistance of the software, can be represented as follows:

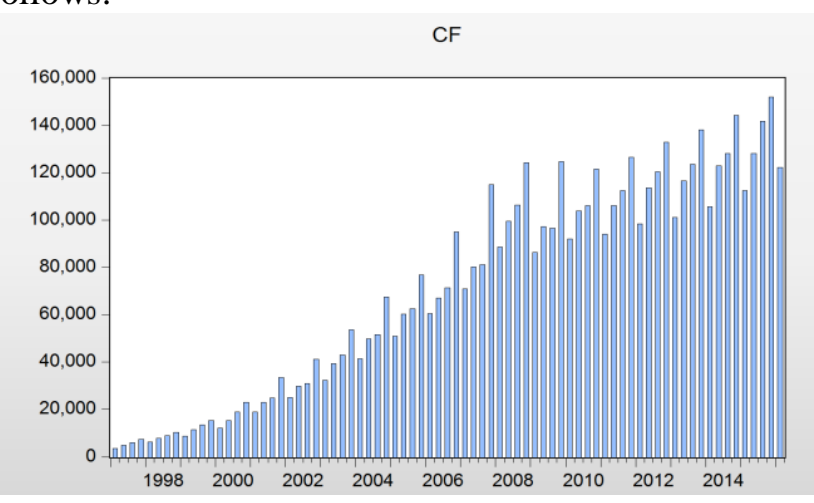

Figure 3.The evolution of the final consumption in Romania during the period $1995-2015$ 
The previous figure helps us to allege that the final consumption recorded slight fluctuations, small increases and decreases during the period of time making the subject of this study but, on an overall basis, there is a marked evolution from one year to the other to be noticed. Similarly to the aspects stated out in the case of the evolution of the Gross Domestic Product, we can notice that the evolution of the final consumption can be analysed as follows:

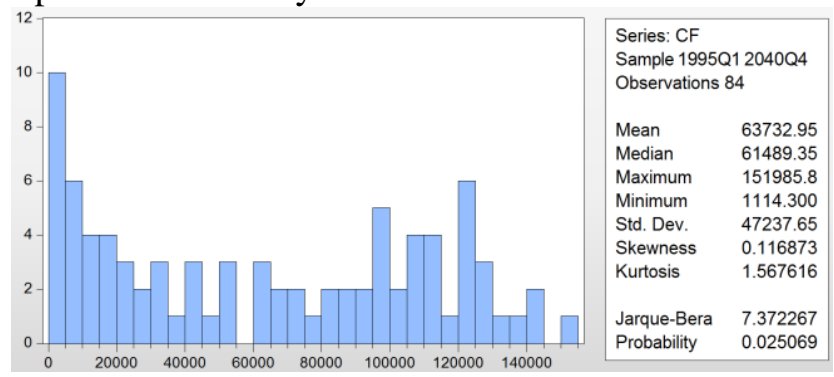

Figure 4.Statistical tests made on the final consumption of Romania during the period $1995-2015$

Applying the instruments of the software package, we established the variation interval of the analysed indicator, setting up the fact that the value of the final consumption is framed between 1114 million RON, in the Q1 1995 and 151,985 million RON, by the end of the year 2015. Meantime, we could establish the fact that the average value of this indicator for the period $1995-2015$ counted for 63,732 million RON. As observed, the values relating to the Skewness and Kurtosis tests allow us to allege that the considered distribution is not a perfectly symmetrical one, the values placed between the minimum and the mean of the data series being prevalent. Out of the two analyses previously submitted it was possible to detach a very important conclusion regarding the modality to analyse the correlation between the two indicators subject of the research - the Gross Domestic Product and the final consumption. Thus, we note the fact that the evolution of the two macroeconomic indicators is a very similar one, marking underlined increases over the $1995-2008$, a diminishing during the next two years and a recover of the two indicators up to the last year included into the time interval subject of the study. Meantime, we can note the fact that the statistical tests made on the data series concerning the two indicators are almost identical. Based on these findings, we can allege the fact that between the value of the Gross Domestic Product and that of the final consumption there is a strong interdependence.

In order to both confirm this allegation and give a better image on the data, we shall proceed to represent them graphically, in a system of bi- dimensional coordinates where the final consumption is inscribed horizontally as an independent variable while the Gross Domestic Product as a dependent variable. 
The result of this representation, as shown by Figure 5, gives us an overall vision helping a proper intuition on the relationship between the two variable. The dot cloud graph of the pairs including the values of the Gross Domestic Product and those of the final consumption shows as follows:

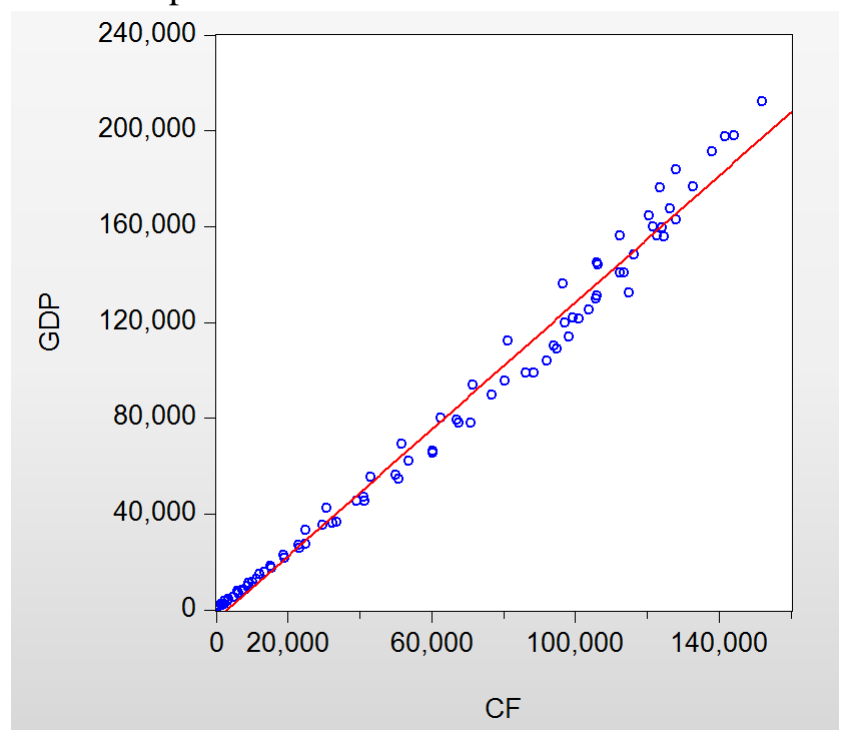

Figure 5.The correlation GDP - final consumption

As noticeable out of the above graph, the pairs of points are describing almost perfectly the trajectory of a line so that the analysis of the studied phenomenon is possible by means of the simple linear regression model. On the basis of the graphical representation we can consider that there is a direct connection between the Gross Domestic Product and the final consumption, in a linear form. The main issue of any regression model consists of the establishment of the model parameters, an operation which can be achieved through the least squares method. For this purpose, we start from the equation of the simple linear regression model:

$$
\mathrm{y}_{\mathrm{t}}=\alpha+\beta * \mathrm{x}_{\mathrm{t}}+\varepsilon_{\mathrm{t}} ; \mathrm{t}=1,2, \ldots, 84
$$

where :

$\hat{y}_{t}=$ the theoretical values of the variable $\mathrm{y}$ obtained depending on the values of the essential factor $\mathrm{x}$ and the values of the estimators of the parameters, respectively $\hat{\alpha}$ and $\hat{\beta}$ only. 
Econometric Model Used for GDP Correlation Analysis and Economic Aggregates

$$
\varepsilon_{t}=y_{t}-\hat{y}_{t}=(\alpha-\hat{\alpha})+(\beta-\hat{\beta}) x_{t} \rightarrow \text { the estimates of the values of the }
$$
error term.

The least squares method implies the minimizing of the following function:

$$
F(\hat{\alpha}, \hat{\beta})=\min \sum_{t=1}^{n}\left(y_{t}-\hat{y}_{t}\right)^{2}=\min \sum_{t=1}^{n}\left(y_{t}-\hat{\alpha}-\hat{\beta} x_{t}\right)^{2}
$$

The minimum condition of this function is the formula:

$$
\begin{aligned}
& F^{\prime}(\hat{\alpha})=0 \Rightarrow n \hat{\alpha}+\hat{\beta} \sum x_{t}=\sum y_{t} \\
& F^{\prime}(\hat{\beta})=0 \Rightarrow \hat{\alpha} \sum x_{t}+\hat{\beta} \sum x_{t}^{2}=\sum x_{t} y_{t}
\end{aligned}
$$

In order to estimate the parameters of this regression model, we used the dedicated software, defining in this frame the equation having as the resulting variable the Gross Domestic Product (GDP), and as the factorial variable the value of the final consumption $(\mathrm{CF})$.

Meanwhile, we considered the fact that this regression model would contain the free term. The estimating method defined in the frame of the programme is the least squares method.

The outcomes obtained show the following:

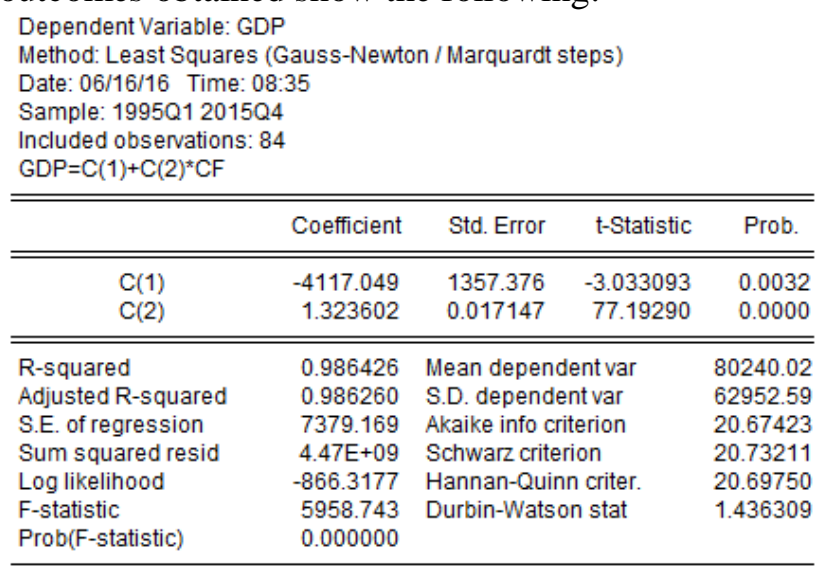

Figure 6.The outcomes of the estimates for the parameters of the regression model

In order to interpret the outcomes obtained with the help of the linear regression model it is necessary to set up, since the very beginning, whether this one can be considered as correct and the results it offers can be utilized in real macroeconomic analyses.

As it can be observed, the probability that this model is a correct one is actually very high - approximately $98.64 \%$-, this conclusion being available on the 
basis of the values established for the $\mathrm{R}$ tests - squared (0.986426) and Adjusted $\mathrm{R}$ - squared (0.986260). In this example, the final consumption, $x$, explains the variation of the Gross Domestic Product, y, at a ratio of 98.64\%. The occurring situation can be considered as normal in the conditions of knowing the fact that in Romania the economic growth over the last years has been substantiated almost exclusively on a policy meant to stimulate the consumption.

Also, the validity of this regression model is confirmed by the values of the F tests - statistical (5958.743 - a value by far superior to the tabled level considered as reference point within the analyses of validity for the macroeconomic models, the value of the $\mathrm{F}$ and $\mathrm{t}$ statistics corresponding to the regression slope is verifying the relation $\mathrm{t}^{2}=\mathrm{F}$, as well as the null risk degree (reflected through the value of the test Prob F - statistic).

For each independent and constant variable, we have the standard error of the coefficient, the test t-Statistic and the probability related to this one. If considering a relevance level of $5 \%$ to work with, since the probability attached to the test t-statistic is inferior to this level for the $\mathrm{CF}$, then the coefficient is considered as significant from the statistical point of view. The coefficient of the free term is not significant since the probability attached to the test t-statistic is by far superior to the significance treshold of $5 \%$. Based on the elements previously mentioned, we can consider the regression model describing the correlation between the value of the Gross Domestic Product and that of the final consumption as being a correct one, reflecting faithfully the real evolution of the two macroeconomic indicators. Thus, it is possible to transcribe the unifactorial linear regression model under the following form:

$\mathrm{GDP}=-4117.049+1.323602 \cdot \mathrm{FC}$

This regression model allows us to set up a series of aspects regarding the relation existing between the two considered variables. To note the fact that between the Gross Domestic Product value and that of the final consumption recorded in Romania there is a significant direct relationship. Thus, we can allege the fact that the increase with one million RON of the final consumption would lead to the increase with 1.323602 million RON of the values of the Gross Domestic Product, consequently the direct relation between the two variables is obvious.The negative value of the free term emphasizes the fact that the variables not included in the econometric model are exerting a negative influence on the Gross Domestic Product evolution, which leads to the conclusion that the utilized model, although a correct and properly chosen one, may be further developed and studied thoroughly in order to secure better outcomes.

Based on the analysis previously performed, we can allege that the Gross Domestic Product is decisively influenced by the final consumption. 
Econometric Model Used for GDP Correlation Analysis and Economic Aggregates

By taking into consideration the degree of co-integration between the two variables, the data for $\mathrm{CF}$ were differenced, and the result data series was named DCF. The GDP series was likewise differentiated under the alias DGDP. graph:

The comparison between the two series is represented in the following

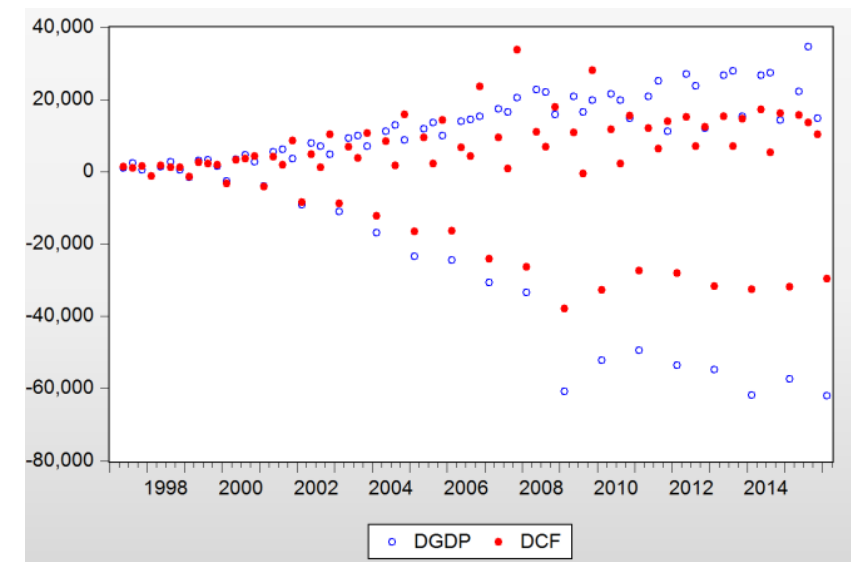

Figure 7. The dot plot for DGDP and DCF series

By analyzing the two sets of dots, we conclude that is reasonably to draw a linear regression between the DGDP and DCF. The parameters of the model are represented in figure 8 .

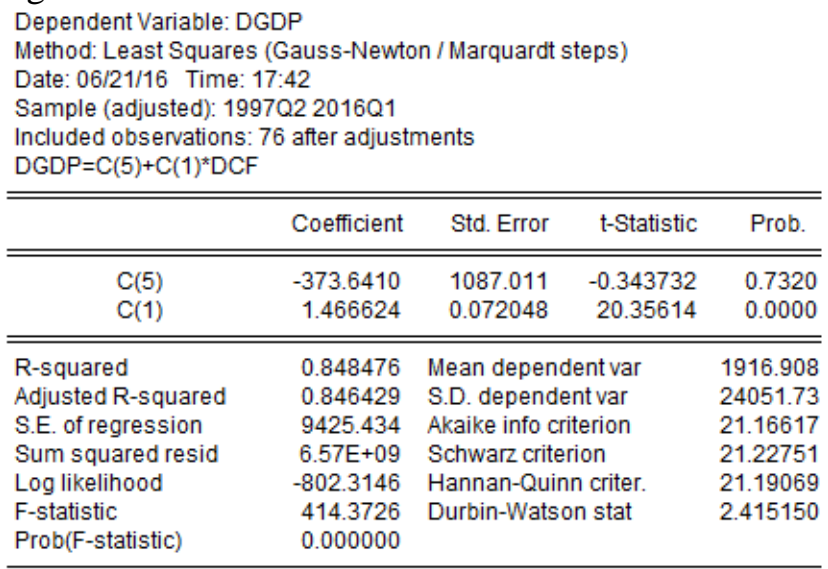

Figure 8. Simple linear regression between GDP and Final Consumption differenced series

As it can be seen, the R-squared and Adjusted R-squared have significant close to unit values, which means that the probability of the model is likewise 
proper and relevant: the final consumption explains the evolution of GDP (as specified, differenced series), for a probability of more than $84 \%$.

The formula of the model can be written:

$\mathrm{DGDP}=-373.6410+1.466624 * \mathrm{DCF}+\varepsilon$

The parameters of the regression model reveal the fact that if DCF increases by one million lei, the DGDP will likewise rise by approximately 1,46 million lei. The value of the free term is significant, leading to the conclusion that the influence of other factors should be taken into account.

\section{The econometric model of the analysis of the correlation between the} Gross Domestic Product and the value of investments

In the considered data series, the investments are represented by the value of gross formation of fixed capital (F). The data were drawn from the same source as the final consumption. The regression model which is the scope of this section will try to outline the contribution of the investments to the evolution of GDP. By taking into account the fact that, partially, the investments produce effects at a later moment, we have resorted to create an alternative dataset, with a gap of two years, and the values were processed by differencing (under the series name DF). Therefore, we have chosen a multiple regression model, whose structure is based on the following equation:

$$
\mathrm{GDP}_{\mathrm{Qi}}=\alpha+\beta_{1} * \mathrm{FB}_{\mathrm{Qi}-8}+\beta_{2} * \mathrm{FB}_{\mathrm{Qi}-7}+\beta_{3} * \mathrm{FB}_{\mathrm{Qi}-6}+\beta_{4} * \mathrm{FB}_{\mathrm{Qi}-5}+\varepsilon
$$

Where QiN represents the $i$ trimester of the dataset, in chronological order.

As specified, the dataset was subjected to differencing. The datasets are represented in figure 9 as a comparative chart (DF1 - DF4 are the four values of the independent variable for a given value of GDP):

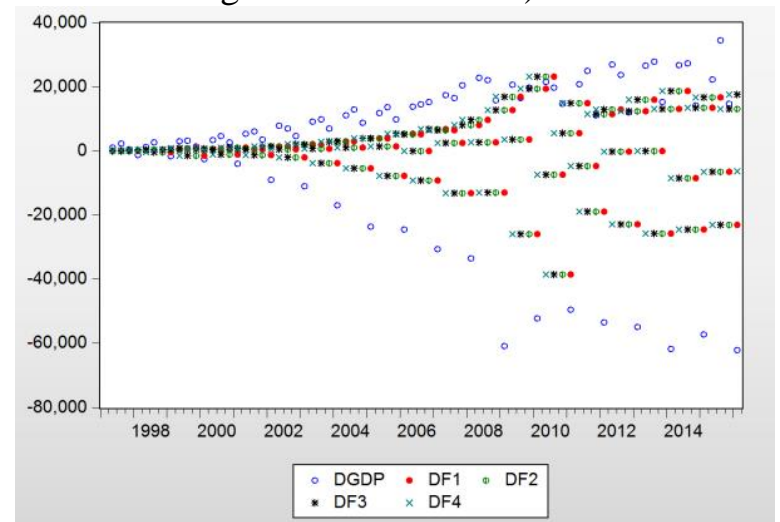

Figure 9. The dot plot for DGDP and four corresponding DF series 
Econometric Model Used for GDP Correlation Analysis and Economic Aggregates

Based on the comparative graphical representation in the above chart, we focus on the design of the regression model. By using the least squares method for estimation, the parameters of the model are shown in figure 10:

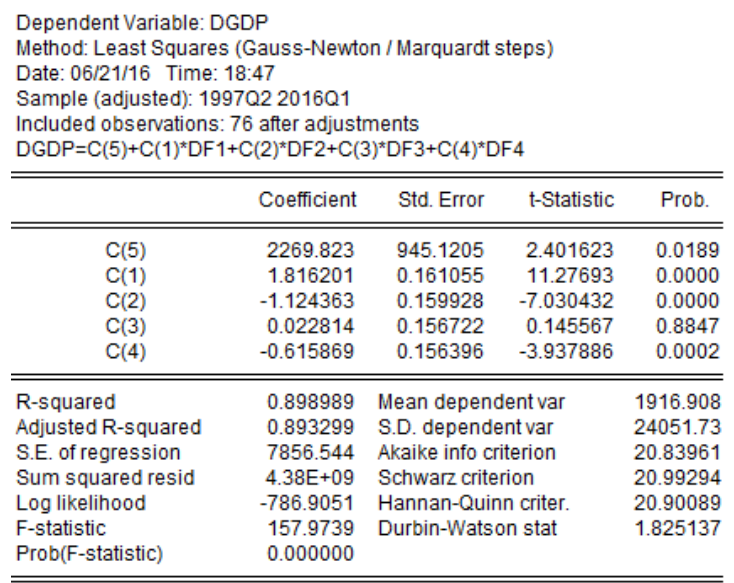

Figure 10. Multiple regression model based on the gross formation of fixed capital

The model offers a reasonable degree of accuracy, since both R-squared and adjusted R-squared are above 0.89 , giving a probability greater than $89 \%$ for the model.

In this respect, the model can be written under the following form:

$\mathrm{GDP}=2269.823+1.816201 * \mathrm{~F} 1+(-1.124363) * \mathrm{~F} 2+0.022814 * \mathrm{~F} 3+$ $(-0.615869) * \mathrm{~F} 4+\varepsilon$

The parameters of the model lead to the following conclusions:

- The most significant influence is exerted by F1, which represents the gross formation of fixed capital recorded two years previously. For an increase of one million lei of this indicator, the GDP is supposed to grow by more than 1.8 million lei;

- A positive influence, but of lower amplitude, corresponds to the F3 variable, that is the gross formation of fixed capital which occurred six semester before the reference;

- The F2 and F4 variables reveal indirect influences on the Gross Domestic Product.

\section{Conclusions}

Our paper shows that an econometric model, generally speaking, might be efficiently used in order to underline the evolution, correlation and dependence between the considered indicators (variables). The use of a series of data for 
84trimesters in the model, exposed a strong connection. We have used some figures and graphs which express more clearly those interdependencies. Based on the analyses previously performed, we can allege that the Gross Domestic Product is decisively influenced by the final consumption. We underline that the Romanian economy of the last 21 years has been constructed almost exclusively on the basis of the consumption stimulation and less on promoting a proper investment strategy.

Taking into account the importance of investments in the national economy, we have proposed a multiple linear regression model, which outlines the influence of the gross formation of fixed capital on the evolution of GDP.

The models were tested, and the results of the tests are compliant with the requirements, granting confidence for the future use of the models.

Our further research will take into consideration the correlation between the Gross Domestic Product and the other aggregates.

\section{REFERENCES}

[1]Andrei, T.,Bourbonnais, R. (2008),Econometrics; Economica Publishing House, Bucharest;

[2]Anghel, M.G. (2014),Econometric Model Applied in the Analysis of the Correlation between Some of the Macroeconomic Variables; Romanian Statistical Review, (Supplement no. 1): 88-94;

[3]Anghelache, C., Isaic-Maniu,Al., Mitruț, C., Voineagu, V. (2011), The

National Accounts System: syntheses and case studies; Economica Publishing House, Bucharest;

[4]Anghelache, C.,Anghel, M.G.,Prodan, L.,Sacală, C.,Popovici, M. (2014),Multiple Linear Regression Model Used in Economic Analyses; Romanian Statistical Review(Supplement no. 10): 120-127;

[5]Benjamin, C.,Herrard, A.,Hanee-Bigot, M.,Tavere, C. (2010),Forecasting with an Econometric Model; Springer;

[6]Chamberlin, G. (2011),Gross Domestic Product, Real Income and Economic Welfare; Economic \& Labour Market Review, 5(5): 5 - 25;

[7]Corbae, D., Durlauf, S.N., Hansen, B.E. (2006),Econometric Theory and Practice - Frontiers of Analysis and Applied Research; Cambridge University Press;

[8]Dougherty, C. (2007),Introduction to Econometrics; Oxford University Press; [9]Fox, M., Dodge, E. R. (2012),Economics Demystified; McGraw Hill Companies Inc.;

[10]Ghysels, E., Osborn R.D. (2001),The Econometric Analysis of Seasonal

Time Series; Cambridge University Press; 
Econometric Model Used for GDP Correlation Analysis and Economic Aggregates

[11]Goodwin, N.R. (2008),Macroeconomics for the Twenty-First Century. Tufts University, series GDAE Working Papers no. 03-02;

[12]Heathcote, J. et. al. (2009), Quantitative Macroeconomics with

Heterogeneous Households; Federal Reserve Bank of Minneapolis in its series Staff Report with number 420;

[13]Hindls, R., Hronova, S. (2012), Reflection of Economic Development of Selected Countries in the Structure of Final Consumption Expenditure;

Politickáekonomie, (4): 425-441;

[14]Klär, E. (2013),Potential Economic Variables and Actual Economic Policies in Europe; Intereconomics, 48 (1): 33 - 40;

[15]Mandel, M., Tomšík, V. (2003),The Consumption Function and Ricardian Equivalence in a Small Open Economy; University of Economics, Prague in Politickáekonomie;

[16]Mazurek, J. A. (2012), Comparison of GDP Growth of European Countries during 2008-2012 Period from Regional and other Perspectives; University Library of Munich, Germany in MPRA Paper with number 51178;

[17]Nayyar, D. (2007),Macroeconomics in Developing Countries;

BancaNazionaledelLavoro Quarterly Review, 60 (242): 249-269;

[18]Piroi, M., Păunică, M. (2015), How Technology can Help in Reducing

Romania's Budget Deficit; Proceedings of the 15th European Conference on eGovernment 2015: ECEG 2015;

[19]Soren, J.,Nielsen, M.Ø. (2010),Likelihood Inference for a Fractionally

Cointegrated Vector Autoregressive Model; CREATES Research Papers 2010-24,

School of Economics and Management, University of Aarhus;

[20]Stanciu, A.P., Stoicuţa, N.E. (2010),European Econometric Analysis of the Interconnection of Consumption and GDP Approached According to Eviews Program; Annals of the University of Petrosani - Economics, 10 (4): 317-326; [21]Stancu, S., Andrei, T., Iacob, A.I., Tusa, E., (2008), Introduction into Econometrics by Using Eviews; Economica Publishing House, Bucharest; [2]vanEijck, K., Majorana, M. (2013),Consumption Patterns, in Ruth Towse \& Christian Handke (ed.) ,Handbook on the Digital Creative Economy”;Books, Edward Elgar, number 14906, 6;

[23]Vargas, G. (2013),Relevant Macroeconomics for Developing Countries: A Contribution to Pluralist Macroeconomics. Int. J. of Pluralism and Economics Education, 4 (1): 61-77;

[24]www.insse.ro - official site of the National Institute of Statistics of Romania; [25]The Statistical Year Book of Romania, issues 2002, 2005, 2006, 2007, 2008, 2009, 2010, 2011, 2012, 2013, 2014. 